\title{
Matris Normları ile Bir Matris Oyununun Adilliğinin Gösterilmesi
}

\author{
Demonstration of the Fairness of a Matrix Game with Matrix Norms
}

\author{
Burhaneddin IZGGí1 ${ }^{1}$, Murat ÖZKAYA ${ }^{1}$ (D) \\ ${ }^{1}$ Istanbul Teknik Üniversitesi, Fen-Edebiyat Fakültesi, Matematik Mühendisliği Bölümü, 34469 Maslak, İstanbul
}

$\ddot{\mathbf{O} z}$

$\mathrm{Bu}$ çalışmada, matris oyunlarını çözmek ve bu tür oyunları kurmak için literatüre yeni kazandırılmış ve yalnızca getiri matrisinin matris normlarından oluşan bir yöntemi kullanarak herhangi bir matris oyununun adil bir oyun olup olmadığını belirlemeyi hedefledik. Bunu yapmak için Taş-Kağıt-Makas oyununun genişletilmiş bir versiyonu olan Taş-Kağıt-Makas-Kertenkele-Spock (Rock-Paper-Scissors-Lizard-Spock) oyununu ana örnek olarak kullandık. Öncelikle oyunun gerçek sonucunu görmek için ilgili oyunu literatürde bilenen yöntemleri kullanarak çözdük. Daha sonra, herhangi bir lineer sistem çözmeksizin, sadece getiri matrisinin 1 ve ${ }^{\infty}$ normlarını kullanarak, bu oyunun adil bir oyun olup olmadığını detaylı bir şekilde farklı senaryolar altında yeni yöntemi kullanarak inceledik. Bunların yanı sıra, kare getiri matrisine sahip oyunların adil olup olmadığı çok daha hızlı bir şekilde gösterecek, getiri matrisinin determinantını içeren yeni bir teorem sunduk ve ispatladık. Son olarak sunduğumuz yeni teoremin uygulamalarını Taş-Kağıt-Makas-Kertenkele-Spock ve örnek olarak ele aldığımız diğer matris oyunları için de yaparak hızlı bir şekilde sonuçların elde edilebileceğini gösterdik.

Anahtar Kelimeler: Oyun teorisi, Sıfır toplamlı oyun, Matris oyunları, Matris normları, Taş-kağıt-makas

\begin{abstract}
In this study, we aim to determine whether matrix game is fair or not, with a recently introduced method which consists of only the matrix norms of the payoff matrix. We use Rock-Paper-Scissors-Lizard-Spock game, which is an extension of the Rock-Paper-Scissors game, as the main example. First, we solve the game with the well-known method in the literature in order to have the actual results for comparing with the results obtained by the new approaches. We then investigate whether the game is fair or not with different scenarios, by using only 1 and $\infty$ norms of the payoff matrix without solving any linear system. In addition to these, we present and prove some new theorems, which contains only the determinant of the payoff matrix, for checking the fairness of the square matrix games. Finally, we show that the results may be obtained fast by illustrating the applications of the proposed theorem to Rock-Paper-Scissors-Lizard-Spock and other example games.
\end{abstract}

Keywords: Game Theory, Zero-Sum game, Matrix games, Matrix norms, Rock-paper-scissors

\section{GíRiş}

Oyun teorisi rekabetin bulunduğu ortamlarda, oyuncuların karar verme aşamalarını matematiksel olarak inceleyen bir teori olarak tanımlanabilir. Oyun teorisinin temelleri tarihte ilk kez 2. Dünya savaşı esnasında gerçekleşen ve mücadele içeren çeşitli olaylara karşı matematiksel yaklaşımların uygulanması sonucu atılmışırı [1]. Bu alanda yazılmış bilinen ilk kitap J. Von Neumann ve O. Morgenstern tarafından kaleme alınan Oyunlar Teorisi ve Ekonomik Davranış (Theory of Games and Economic Behaviour) isimli eserdir [2]. Kitabın yayınlanmasından bu yana onlarca yıl geçmiş olmasına rağmen oyun teorisi bugün de ilk günkü kadar güncel ve çok daha gelişmiş bir şekilde bilim dünyasında varlığını sürdürmektedir. Bu süreç içerisinde oyun teorisi fizikten sosyal bilimlere, ekonomiden tarıma, birçok bilim dalında kendisine yer edinmiş ve uygulama alanı bulmuştur. 1959 yılında Haywood, 2. Dünya savaşındaki iki savaş taktiğini incelemiş ve askeri doktrinler ile oyun teorisi arasında bir benzeşim geliştirmiştir [3]. Shenoy 1979 yılında yayınladığı makalesinde n-kişilik işbirlikli oyunlardaki koalisyon oluşumu sorusuna yanıt aramıştır [4]. Nash 1994 yılında yayınladığı ve oyun teorisinde çığır açan çalışmasında işbirlikçi 
oyunlardaki denge noktalarını incelemiş ve bu çalışmasının sonucunda Nobel ekonomi ödülüne layık görülmüştür [5]. 2007 yılında Okura rekabetin Japon sigorta şirketlerine yapılan yatırımları nasıl etkilediğini oyun teorisini kullanarak incelemiştir [6]. 2010'da Gu, hareketli bir hedefi sensor ağıyla takip etme problemini incelemiş ve bu çalışmasında hedef tahminini sıfir toplamlı bir oyun şeklinde modellemiştir [7]. 2017 yılında Rezazadeh ve arkadaşları tehlikeli boru hatlarındaki devriye nöbetlerinin programlanabilmesi için oyun teorisine dayalı bir yöntem sunmuştur [8].

İzgi ve Özkaya literatürde ilk olarak matris normları ile oyun teorisini 2018 yılında yayınladıkları makale ile bir araya getirdiler [9]. Yaptıkları bu çalışmada iki kişilik sıfır toplamlı matris oyunlarının hem çözümüne hem de bu tür oyunların kurulumuna yönelik getiri matrisinin yalnızca 1 -normunu ve ${ }^{\infty}$-normunu esas alan yeni bir yaklaşım sunulmuştur. Böylece yüksek boyutlu bir matris oyununun, hızlı bir şekilde yaklaşık çözümünün elde edilebilmesi ve karma stratejiler kümesinin en büyük ve en küçük elemanları için alt ve üst sınırların belirlenebilmesi mümkün hale getirilmiştir. Aynı yıl Özkaya ise yüksek lisans tezinde oyun teorisinde matris normlarının rollerini detaylı bir şekilde incelemiştir [10]. Bunların yanı sıra, İzgi ve Özkaya [9]'da sunmuş oldukları bu yeni yöntemlerini sıfir toplamlı olmayan iki kişilik bimatris oyunları için geliştirerek ve literatürde bilinen ünlü örneklerle de bu yaklaşımlarını güçlendiren ayrı bir çalışmaya imza attılar [11].

Biz bu çalışmada, ilk olarak iki kişilik sıfır toplamlı matris oyunlarının adilliğini $[9,11]$ çalışmalarıyla literatüre kazandırılmış olan yeni yöntemi kullanarak göstermeyi hedefledik. Bunun yanı sıra, kare getiri matrisine sahip bir oyunun adil olup olmadığını hızıı bir şekilde gösterecek, getiri matrisin sadece determinantına bağlı yeni bir teorem sunduk ve ispatladık. Ayrıca, kare matrislerin özel bir hali olan ters-simetrik matrisler için de lineer cebir kitaplarında verilen bir teoremin oyun teorisi açısından uygulamasını sunduk.

Çalışmamızda ele alınacak olan ana oyun Taş-Kağıt-Makas oyunu olarak bilinen oyunun genişletilmiş bir versiyonu olan ve ilk olarak The Big Bang Theory adlı televizyon dizisinde iki karakter arasında oynanan Taş-Kağıt-Makas-Kertenkele-Spock (TKMKS) olarak isimlendirilen oyundur. $\mathrm{Bu}$ oyunun matematiksel anlamda adil bir oyun olduğu [12]'de Birgen tarafından çizge teorisi yardımıyla 2015 y1lında gösterilmiştir. Biz ise bu çalışmamızda, $[9,11]$ çalışmalarında literatüre kazandırılmış olan yeni yöntemi kullanarak, TKMKS oyunun matematiksel anlamda adil bir oyun olduğunu herhangi bir denklem sistemi çözmeden ve sadece getiri matrisinin 1-normunu ve $\infty$-normunu kullanarak göstermeyi hedeflemekteyiz. Bunlara ek olarak da, bu çalışmada ilk olarak sunmuş olduğumuz teoremleri kullanarak TKMKS oyunu ile birlikte çeşitli matris oyunlarının adilliğini basit bir şekilde göstermeyi amaçlamaktayız. Çalışmanın geri kalan kısmı şu şekilde organize edilmiştir: İkinci bölümde bahsedilen yöntemi uygulamak için kullanılacak gerekli teorik altyapı sunulmuştur. Ayrıca Taş-Kağıt-Makas oyunu bir diyagram yardımıyla gösterilmiş ve oyunun çözümü verilmiştir. Üçüncü bölümde ilk olarak, Taş-Kağıt-Makas-Kertenkele-Spock oyunu ayrıntılarıyla ele alınarak TKMKS oyunun adil bir oyun olduğu ilgili yöntem ve sunulan yeni teoremler kullanılarak gösterilmiştir. Daha sonra çeşitli örnekler için de sunulan yöntemlerin tutarlılığı incelenmiştir. Son bölümde ise makaledeki sonuçlardan kısaca bahsedilmiştir.

\section{BAZI TEORİK YAKLAŞIMLAR VE TAŞ-KAĞIT- MAKAS OYUNU}

$\mathrm{Bu}$ bölümde ilk olarak sıfır toplamlı herhangi bir oyunun çözümünde kullanılacak olan gerekli teorik alt yapıya yer verilecektir. Daha sonra klasik anlamdaki Taş-Kağıt-Makas (TKM) oyununun nasıl oynandığı bir diyagram yardımı ile özetlenecektir. Ayrıca TKM oyunun getiri matrisi, oyun değeri ve karma stratejiler kümesi [13]'te verildiği şekilde sunulacaktır.

Tanım 2.1 [14]: Eğer bir oyunun oyun değeri $v=0$ ise ilgili oyuna adil oyun, $v \geq 0$ ise oyun I. Oyuncu lehine, $v \leq 0$ ise oyun II. Oyuncu lehine bir oyun denir.

Tanım 2.2 [9]: $A \in \mathbb{R}^{m \times n}$ bir matris ve $\|A\|_{\infty}$ ise $A$ 'nın h. satırının girdilerinin mutlak değer toplamı olsun. $\mathrm{Bu}$ durumda A matrisinin $\mathrm{h}$. satırının silinmesiyle elde edilen $B \in \mathbb{R}^{(m-1) \times n}$ matrisine A matrisinin satırsal olarak indirgenmiş matrisi denir. Aynı şekilde $A \in \mathbb{R}^{m \times n}$ bir matris, $\|A\|_{1}$ ise $A$ 'nın s. sütununun girdilerinin mutlak değer toplamı olmak üzere A matrisinin s. sütununun silinmesiyle elde edilen $B \in \mathbb{R}^{m \times(n-1)}$ matrisine A matrisinin sütunsal olarak indirgenmiş matrisi denir.

Teorem 2.3 [9]: $A \in \mathbb{R}^{m \times n}$ iki kişilik sıfır toplamlı oyunun getiri matrisi ve $B, A$ matrisinin satırsal olarak indirgenmiş matrisi olmak üzere, $v$ oyun değeri için

$$
\begin{aligned}
& |v| \geq 1 \text {, ise } \frac{\|B\|_{\infty}}{\|A\|_{\infty}} \leq|v| \leq\|A\|_{1} \\
& |v| \leq 1 \text { ve } v \neq 0 \text {, ise } \frac{1}{\|A\|_{1}} \leq|v| \leq \frac{\|A\|_{\infty}}{\|B\|_{\infty}}
\end{aligned}
$$

eşitsizlikleri sağlanır.

Teorem 2.4 [9]: $A \in \mathbb{R}^{\mathrm{m} \times \mathrm{n}}$ iki kişilik sıfır toplamlı bir oyunun pozitif girdili getiri matrisi olsun. Karma stratejiler kümesinin en büyük ve en küçük elemanları, sırasıyla $P_{\max }$ ve $P_{\min }$, için 
$L=\max \left\{\frac{1-\frac{|v|}{\|A\|_{1}}}{m-1}, \frac{|v|}{\|B\|_{\infty}}\right\}$ için $p_{\max } \geq L$

$U=\min \left\{\frac{1-\frac{|v|}{\|B\|_{1}}}{m-1}, \frac{|v|}{\|A\|_{\infty}}\right\}$ için $p_{\min } \leq U$

eşitsizlikleri sağlanır.

Önerme 2.5: $A \in \mathbb{R}^{\mathrm{m} \times \mathrm{n}}$ iki kişilik sıfır toplamlı bir oyunun getiri matrisi, ${ }^{v}$ oyun değeri olsun. Ayrıca, $x=|\min (A)|$ ve $y=-|\max (A)|$ olmak üzere, $X$ (ya da $Y$ ) $\in \mathbb{R}^{\mathrm{m} \times \mathrm{n}}$ bütün girdileri $x$ ( $y a$ da $y$ ) olan bir matris olsun. Bu durumda, ötelenmiş oyununun pozitif girdili getiri matrisi $A+X$ (ya da negatif girdili getiri matrisi $A+Y$ ) ve bu oyunun oyun değeri $v+x(y a d a v+y)$ olur.

İspat. Önerme 2.5, [9]'daki Önerme 2.7'nin bir genellemesi olup, ispatı benzer şekilde kolayca yapılabilir.

Sonuç 2.6 : Her matris oyunu aynı strateji kümesi ile beraber kısmen ya da tamamen pozitif (ya da negatif) girdili matris oyununa dönüştürülebilinir.

Eğer adilliğini inceleyeceğimiz oyunun getiri matrisi bir kare matris veya ters-simetrik bir matris ise aşağıdaki teoremler yardımıyla oyunun adilliği hakkında daha hızlı şekilde bir sonuç elde edilebilinir.

Teorem 2.7: $A \in \mathbb{R}^{n \times n}$ iki kişilik sıfir toplamlı herhangi bir oyunun ters simetrik olmayan getiri matrisi olsun. Eğer $A$ adil bir oyunun getiri matrisi ise $\operatorname{det}(A)=0$ ' $d ı r$.

İspat. $A \in \mathbb{R}^{n \times n}$ bir adil oyunun getiri matrisi ve $p \in \mathbb{R}^{1 \times n}$ bu oyunun strateji vektörü olsun. Diğer taraftan, herhangi bir oyunun oyun değerinin $p A=v \in \mathbb{R}^{1 \times n}$ şeklinde hesaplanabileceğini biliyoruz. $A$ adil bir oyunun ( $v=0$ ) getiri matrisi olduğundan bu sistem $p A=0$ homojen bir sisteme dönüşür.

$\mathrm{Bu}$ sistemin, $\operatorname{det}(A) \neq 0$ olduğu durumda $p=0$ aşikar çözümüne sahip olduğu açıktır. Öte yandan, oyun teorisinin doğası gereği, oyunun stratejisinin 0 vektöründen farklı bir vektör olması gerçeğinden yola çıkarak bu durumun sistemin istenen bir çözümü olamayacağı sonucuna ulaşılır.

Böylece, $\operatorname{sistemin~çözümünü~} \operatorname{det}(A)=0$ olduğu durum için incelemek gerekir. Yani $A$ getiri matrisinin tekil olması durumunda sistemin ya çözümünün olmadığ 1 ya da sonsuz çözüme sahip olduğu açık bir gerçektir. ${ }^{A}$ adil bir oyunun getiri matrisi olduğuna göre sistemin sıfırdan farklı $(p \neq 0)$ bir çözümü olmak zorundadır. Sonuç olarak, $p A=0$ sisteminin sıfırdan farklı bir çözümünün ( $p$ strateji vektörünün) olması için $\operatorname{det}(A)=0$ olması gerekmektedir.

Benzer şekilde kare matrislerin özel bir hali olan ters-simetrik matris oyunları için Jacobi teoremi olarak da bilinen aşağıdaki teoremi kullanabiliriz.

Teorem 2.8 (Jacobi Teoremi) [15]: $A \in \mathbb{R}^{n \times n}$ ters-simetrik bir matris olmak üzere eğer $n$ tek ise $A$ 'nın determinantı sifirdır.

Not 1: Eğer $\mathrm{A} \in \mathbb{R}^{\mathrm{n} \times \mathrm{n}}$ getiri matrisi $\mathrm{n}$ çift olmak üzere bir ters-simetrik bir matris ise oyunun adilliğini göstermek için buradaki teorik sonuçlar direk kullanılamayacağından, matris normları ile [9]'da verilen yaklaşımın kullanılması gerekmektedir.

Not 2: Matlab, Mathematica gibi programlarda işlem yapılırken yuvarlama hatalarından dolayı determinantın beklendiği gibi tam olarak 0 (sıfira oldukça yakın, örneğin $10^{-23}$ gibi) çıkmayabileceği unutulmamalıdır.

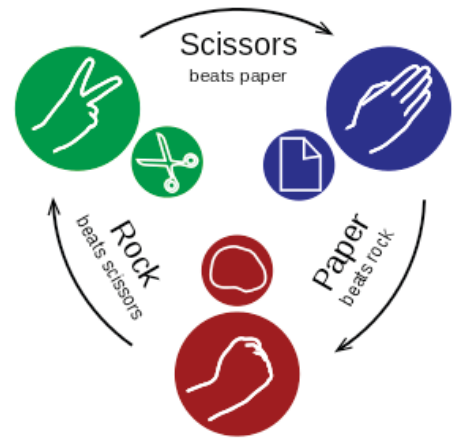

Şekil 1. Taş-kağıt-makas oyunu [16]

Taş-Kağıt-Makas oyununun getiri matrisi aşağıdaki gibidir.

$$
A=\left[\begin{array}{cccc} 
& T & K & M \\
T & (0,0) & (-1,1) & (1,-1) \\
K & (1,-1) & (0,0) & (-1,1) \\
M & (-1,1) & (1,-1) & (0,0)
\end{array}\right]
$$

Bu oyunun oyun değeri $v=0$ ve karma stratejiler kümesi $S=\{0.33,0.33,0.33\}$ şeklinde olduğu ilgili kaynakta verilmiştir [13]. Biz bu oyunun genellemesi olan TKMKS oyunu üzerine yoğunlaşıp, oyunun adilliğini yukarıda verilen yaklaşımlar ve teoremler yardımıyla göstereceğiz. 


\section{UYGULAMALAR}

\subsection{TKMKS Oyununun Adil Olduğunun Belirlenmesi}

Bu bölümde ilk olarak, Taş-Kağıt-Makas-Kertenkele-Spock oyunun kurallarını bir diyagram ile gösterip getiri matrisini sunacağız. Ardından, bu oyunun adil bir oyun olduğunu [9, 11] çalışmalarında sunulan yeni yöntem ile göstereceğiz. Son olarak, kare getiri matrisine sahip oyunlar için verdiğimiz Teorem 2.8'i kullarak oyunun adil olduğunu diğer bir yöntemle çok daha hızlı bir şekilde göstereceğiz.

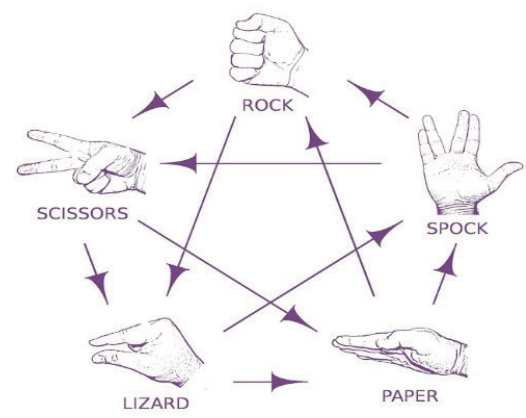

Şekil 2. Taş-kağıt-makas-kertenkele-spock oyunu [17]

Taş-Kağıt-Makas-Kertenkele-Spock oyununun getiri matrisini klasik Taş-Kağıt-Makas oyununun getiri matrisine benzer şekilde oluşturursak, ${ }^{A}$ bimatrisi

$$
\left[\begin{array}{cccccc} 
& T & K & M & K r & S p \\
T & (0,0) & (-1,1) & (1,-1) & (1,-1) & (-1,1) \\
K & (1,-1) & (0,0) & (-1,1) & (-1,1) & (1,-1) \\
M & (-1,1) & (1,-1) & (0,0) & (1,-1) & (-1,1) \\
K r & (-1,1) & (1,-1) & (-1,1) & (0,0) & (1,-1) \\
S p & (1,-1) & (-1,1) & (1,-1) & (-1,1) & (0,0)
\end{array}\right]
$$

olarak elde edilir.

İki kişilik sıfır toplamlı oyunlar bir optimizasyon problemine dönüştürülerek çözülebileceği gibi literatürde stratejilerin eşitlenmesi olarak bilinen bir diğer yöntemle de elde edilebilir. Fakat biz bu çalışmamızda literatüre [9] nolu çalışmada kazandırılmış yeni yöntemi kullanarak çözmeye odaklandığımız için oyunun gerçek çözümünü görmek adına, [18]'deki bağlantı yardımıyla sonuçları her iki oyuncunun da getiri matrislerini kullanarak elde ettik. Bunun sonucunda elde edilen sonuçlar her iki oyuncu için, yani I. oyuncu ve II. oyuncu için, aşağıdaki gibidir:

Oyun değerini her iki oyuncu için $v=0$ ve karma stratejiler kümesini ise $S=\{0.2,0.2,0.2,0.2,0.2\}$ olarak bulduk. Oyun değeri sıfir olduğu için bu oyun adil bir oyundur.

Biz bu çalışmamızda, [9]'da sunulan, [10]'da detaylı bir şekilde incelenen ve [11]'de de geliştirilen yöntemi kullanarak bir oyunun adil bir oyun olduğuna nasıl karar verilebileceğini daha öncede belirttiğimiz gibi Taş-Kağıt-Makas-Kertenkele-Spock oyunu üzerinden göstereceğiz. Buna ek olarak, bu çalışmada sunduğumuz Teorem 2.8 ile hızlı bir şekilde sonuca ulaşabileceğimizi ortaya koyacağız.

Çözüm aşamasına geçmeden önce ilk olarak ilgili oyun için verilen getiri matrisini iki adet matris oyununa dönüştürüyoruz. Yani I. ve II. oyuncuların getiri matrislerini, sırasıyla $A_{1}$ ve $A_{2}$, ayrı ayrı olarak inceliyoruz. II. oyuncu için de getiri matrisi aşağıda açık bir şekilde verilen $A_{1}$ matrisine benzer şekilde oluşturulursa $A_{1}=-A_{2}$ olduğu görülecektir. Bunun anlamı diğer bir deyişle, bu oyunun iki kişilik sıfır toplamlı bir oyun olduğudur [19]. Bu yüzden, oyunu yalnızca $A_{1}$ ya da $A_{2}$ matrislerinden birini kullanarak incelemek yeterli olacaktır. Biz bu çalışma boyunca $A_{1}$ matrisini, yani satır oyuncusunun (I. oyuncu) matrisini kullanarak işlemlere devam edeceğiz.

Daha sonra Teorem 2.4'ü kullanabilmek için aşağıda satır oyuncusu için oluşturduğumuz getiri matrisini, Önerme 2.5 'te belirtildiği şekilde pozitif girdili bir getiri matrisine dönüştürüyoruz. Bunun için tüm girdileri $x=1$ olan $5 \times 5$ boyutundaki $X$ matrisi ile $A_{1}$ matrisini toplayarak aşağıdaki ötelenmiş getiri matrisini elde edilir.

Satır oyuncusu için oluşturulmuş getiri matrisi,

$A_{1}=\left[\begin{array}{cccccc}T & 0 & -1 & 1 & 1 & -1 \\ K & 1 & 0 & -1 & -1 & 1 \\ M & -1 & 1 & 0 & 1 & -1 \\ K r & -1 & 1 & -1 & 0 & 1 \\ S p & 1 & -1 & 1 & -1 & 0\end{array}\right]$

şeklinde ve ötelenmiş oyunun getiri matrisi ise

$A_{1}+X_{=}\left[\begin{array}{cccccc}T & 1 & 0 & 2 & 2 & 0 \\ K & 2 & 1 & 0 & 0 & 2 \\ M & 0 & 2 & 1 & 2 & 0 \\ K r & 0 & 2 & 0 & 1 & 2 \\ S p & 2 & 0 & 2 & 0 & 1\end{array}\right]$

şeklindedir.

Teorem 2.3'de verilen eşitsizlikleri kullanabilmek için ötelenmiş getiri matrisinin ilgili matris normları şöyledir: $\left\|A_{1}+X\right\|_{1}=5,\left\|A_{1}+X\right\|_{s}=5$ ve $B_{1}+X, A_{1}+X$ matrisinin satırsal olarak indirgenmiş matrisi olmak üzere $\left\|B_{1}+X\right\|_{\infty}=5 . \mathrm{Bu}$ hesaplamaların ve ilgili teoremdeki eşitsizliğin kullanılması ile $1 \leq v_{A_{1}+X} \leq 5$ sonucuna ulaş1lir.

Oyun değerinin yaklaşık değerini bulabilmek için metodun kullanıldığ diğer çalışmalarda da $[9,11]$ olduğu gibi oyun değeri için bulunan bu aralıktan geçici (dummy) ve keyfi bir oyun değeri seçilmelidir. Yöntemin herhangi bir 
keyfi seçim altında çalıştığını göstermek için iki farklı geçici oyun değeri seçerek iki farklı senaryo üzerinde çalışacağız.

Senaryo 1.: $v_{A_{1}+X}^{\prime}=1$ olsun.

Teorem 2.4'teki eşitsizliklerde geçici oyun değerimizi yerine yazarsak,

$$
\begin{gathered}
L=\max \left\{\frac{1-\frac{1}{5}}{5-1}, \frac{1}{5}\right\}=\max \{0.2,0.2\} \text { için } \\
p_{\max } \geq L=0.2 \\
U=\min \left\{\frac{1-\frac{1}{5}}{5-1}, \frac{1}{5}\right\}=\min \{0.2,0.2\} \text { için } \\
p_{\min } \leq U=0.2
\end{gathered}
$$

sonuçları elde edilir. Yukarıda bulduğumuz eşitsizlikleri de göz önünde bulundurarak karma stratejiler kümesinin elemanlarını örneğin $p_{\max }=p_{\min }=p_{1}=p_{2}=p_{2}=0.2$ şeklinde seçebiliriz. Bu senaryo ve seçim sonucunda karma stratejiler kümesi $S_{1}^{*}=\{0.2,0.2,0.2,0.2,0.2\}$ olarak elde edilir.

Sonuç 2.6'daki gerçeği kullanarak, yani ötelenmiş bir matris oyununun karma stratejiler kümesinin aynı kaldığı bil-

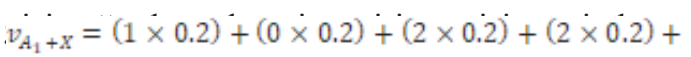
$(0 \times 0.2)=1$

olarak hesaplanır. Elde ettiğimiz $v_{A_{1}+X}=1$ değeri Önerme 2.5 'ten de görüldügü üzere asıl oyun değerinin $x=1$ kadar ötelenmiş halidir. Bu durumda gerçek oyun değerinin

$v=v_{A_{1}+X}-1=1-1=0$

olduğu açık bir şekilde görülmektedir. Sonuç olarak, oyun değerinin $v=0$ olduğunu göstermiş olduk. Diğer bir deyişle, Taş-Kağıt-Makas-Kertenkele-Spock oyununun bu senaryo yardımıyla adil bir oyun olduğunu göstermeyi başardik.

Senaryo 2.: $v_{A_{1}+X}^{\prime}=3.7$ olsun.

Senaryo 1.'e benzer şekilde $p_{\max }$ ve $p_{\min }$ elemanları için sırasıyla alt ve üst sınırları belirlemek için Teorem 2.4 kullanılarak

$$
\begin{gathered}
L=\max \left\{\frac{1-\frac{3.7}{5}}{5-1}, \frac{3.7}{5}\right\}=\max \{0.065,0.74\} \text { için } \\
p_{\max } \geq L=0.74
\end{gathered}
$$

$U=\min \left\{\frac{1-\frac{3.7}{5}}{5-1}, \frac{3.7}{5}\right\}=\min \{0.065,0.74\} i c ̧ \operatorname{in}$

$$
p_{\min } \leq U=0.065
$$

sonuçları elde edilir. Örnek olarak $p_{\max }=0.74, p_{\min }=p_{1}=p_{2}=p_{2}=0.065$ değerlerini seçiyoruz ve bu durumda karma stratejiler kümesini de keyfi olarak $S_{2}^{*}=\{0.74,0.065,0.065,0.065,0.065\}$ şeklinde belirleyebiliriz. Ötelenmiş getiri matrisinin sütunlarını kul$v_{A_{1}+X}=(1 \times 0.74)+(2 \times 0.065)+(0 \times 0.065)+$ $(0 \times 0.065)+(2 \times 0.065)=1$

olarak ötelenmiş oyun değeri bulunur. Yani $v_{A_{1}+X}=1$ gerçek oyun değerinin $x=1$ ötelenmiş hali olduğundan gerçek oyun değeri

$v=v_{A_{1}+X}-1=0$

olarak elde edilir. $\mathrm{Bu}$ durumda oyuna adil oyun diyebiliriz. Fakat diğer sütunlar için de benzer şekilde hesaplamalar yapılırsa 2 . sütun için $v=-0,675,3$. ve 4 . sütunlar için $v=0.675$, son olarak 5 . sütun için de oyun değeri $v=-0.675$ olarak bulunur. Bu durumda oyunu hemen hemen adil bir oyun olarak nitelendirebiliriz.

Bu tür senaryolar arttırılarak farklı sonuçlar elde edilebilinir. Fakat Senaryo 1.'den de görüldüğü üzere oyunun adil bir oyun olduğunu ilgili yöntem ile göstermeyi başardık.

İkinci çözüm yolu olarak; TKMKS oyununun getiri matrisi terssimetrik olduğundan Teorem 2.8 kullanılarak daha hızlı bir şekilde sonuca ulaşılabilinir. Oyunun getiri matrisinin determinantını hesaplarsak, $\operatorname{det}\left(A_{1}\right)=0$ olduğu görülür ve böylece oyunun adil bir oyun olduğu sonucuna Teorem 2.8'den ulaşılır.

\section{2 Örnekler}

Bu bölümde sıfır toplamlı oyunların çözümü için hem literatüre İzgi ve Özkaya $[9,11]$ tarafından kazandırılmış yeni yöntemi hem de yeni sunduğumuz teoremlerin uygulamalarını TKMKS örneğinden farklı örnekler üzerinde de göstermek için iki adet matris oyun örneğini inceleyeceğiz.

Örnek 1. Getiri matrisi aşağıdaki gibi olan iki kişilik sıfır toplamlı bir oyunu ele alalım.

$$
A=\left[\begin{array}{cccc}
1.75 & 2.75 & -0.25 & -1.25 \\
2.75 & 1.75 & 0.75 & -2.25 \\
-2.25 & -2.25 & -0.25 & 1.75 \\
-1.25 & -3.25 & -0.25 & 0.75
\end{array}\right]
$$

Oyunun gerçek çözümü [18]'deki bağlantı yardımıyla hesaplanırsa, oyun değeri $v=0$ ve karma stratejiler kümesi $S=\{0.25,0.25,0.5,0\}$ olarak bulunur. 
Oyunun adilliğini gösterebilmek için ilk olarak TKMKS oyununa benzer şekilde [9]'da verilen yöntemi kullanacağı. Bunun için öncelikle $A$ getiri matrisini Önerme 2.9 yardımıyla bütün girdileri $x=3.25$ olan $X \in \mathbb{R}^{4 \times 4}$ matrisi ile ötelersek, ötelenmiş getiri matrisi

$$
A+X=\left[\begin{array}{llll}
5 & 6 & 3 & 2 \\
6 & 5 & 4 & 1 \\
1 & 1 & 3 & 5 \\
2 & 0 & 3 & 4
\end{array}\right]
$$

olarak elde edilir. Öte yandan, Teorem 2.3 için gerekli olan matris normları $\|\mathrm{A}+X\|_{1}=14,\|\mathrm{~A}+X\|_{\infty}=16 \mathrm{ve}$ $\|\mathrm{B}+X\|_{1}=13\|\mathrm{~B}+X\|_{\mathrm{s}}=16$ olarak hesaplanır. Teorem 2.3 'ten ötelenmiş oyunun oyun değerinin aralığı olarak da $1 \leq v_{\mathrm{A}+\mathrm{X}} \leq 14$ elde edilir. Geçici oyun değerini ötelenmiş oyun değeri için bulduğumuz bu aralıktan örneğin $v_{\perp+y}^{\prime}=5$ olarak seçelim. Teorem 2.4'ü kullanarak $p_{\max }$ ve $p_{\min }$ için sirasıly alt ve üst sinırları da $p_{\max } \geq 0.31$ ve $p_{\min } \leq 0.21$ olarak buluruz. Karma stratejiler kümemizi ise bu senaryoda $S^{*}=\{0.15,0.32,0.48,0.05\}$ olarak belirleyebiliriz. Sonuç olarak 1., 2., 3. ve 4. sütunları kullanıp geri öteleme yapılarak gerçek oyun değeri hesaplanılacak olursa sirasıyla $0,-$ $0.27,0.07$ ve -0.03 değerleri elde edilir. Yani oyunumuzun yaklaşık olarak adil, diğer bir deyişle hemen hemen adil olduğu yorumunu yapabiliriz. Diğer taraftan, Teorem 2.7'yi kullanırsak $\operatorname{det}(A)=0$ sonucuna ulaşırız ki bu sonuç bize oyunun adil bir oyun olduğunu daha hızlı ve net bir şekilde ortaya koymaktadır.

Örnek 2. $A \in \mathbb{R}^{6 \times 6}$ aşağıdaki gibi sıfır toplamlı iki kişilik bir oyunun getiri matrisi olsun.

$A=\left[\begin{array}{cccccc}-2 & 2 & 1 & 12 & -3 & -8 \\ -2 & -1 & 0 & 1 & 2 & 3 \\ 3 & 7 & 1 & -3 & 7 & -23 \\ -4 & 0 & 0 & -1 & 2 & -3 \\ -1 & -5 & -1 & -3 & -3 & 17 \\ -3 & -1 & 0 & -2 & 0 & 1\end{array}\right]$

[18]'deki bağlantı yardımıyla $A$ oyunu çözülürse oyun değerinin sifir ve karma stratejiler kümesinin ise $S=\{0.2,0,0.3,0,0.5,0\}$ olduğu görülür. Teorem 2.7 yard1miyla da oyunumuzun $A$ getiri matrisinin determinantını hesapladığımızda $\operatorname{det}(A)=0$ olarak karşımıza çıkmaktadır, diğer bir deyişle bu sonuç oyunun adil bir oyun olduğunu göstermektedir.

\section{BULGULAR VE TARTIŞMALAR}

$\mathrm{Bu}$ çalışmamızda herhangi bir matris oyununun adilliğini hem matris normlarını içeren yaklaşımla hem de getiri matrisinin determinantına bağlı teoremler yardımıyla detaylı bir şekilde inceledik.
İlk olarak, literatüre matris oyunlarının çözümü ve kurulumu için yeni kazandırılan ve sadece getiri matrisinin normları üzerine kurulmuş olan yeni metodun herhangi bir matris oyunun adil olup olmadığını göstermede de kullanılabileceğini gösterdik. İncelememizde ana örnek olarak ele aldığımız iki kişilik sıfır toplamlı Taş-Kağıt-Makas-Kertenkele-Spock oyununun bu yeni metot yardımıyla adil (veya seçilen senaryoya da bağlı olarak hemen hemen adil) olduğu sonucuna ulaştık.

Ayrıca, kare getiri matrise sahip bir matris oyununun adilliğini inceleyebilmek için daha hızlı ve net sonuç veren yeni bir metodu teorem olarak sunduk ve ispatladık. Bu yeni metodunun kullanışlılığını da örneklerle ayrıntılı olarak sunduk. Bunlara ek olarak, özel bir kare matris olan ters-simetrik matrisler için literatürde Jacobi Teoremi olarak bilinen teoremin uygulanışını oyun teorisi açısından ele aldık. Bu teorem yardımıyla da Taş-Kă̆ıt-Makas-Kertenkele-Spock oyununun adil olduğunu daha hızlı bir şekilde gösterdik.

\section{KAYNAKLAR}

[1] K. G. Guseinov, K. G,, Akyar, E., Düzce, S.A., (2010). Oyun Teorisi Çatışma ve Anlaşmanın Matematiksel Modelleri, Seçkin, 304s.

[2] Von Neumann, J., Morgenstern, O., (1944). Theory of Games and Economic Behaviour, Princeton University Press, 641s.

[3] Haywood, Jr, O. G., (1954). Military Decision and Game Theory. Journal of the Operations Research Society of America,Vol.2, No.4.Shenoy, P. P., (1979). On Coalition Formation:

A Game Theoretical Approach. International Journal of Game Theory, Vol. 8, Issue 3, $133-164$.

[5] Nash, J. F., (1950). The Bargaining Problem. Econometrica: Journal of the Econometric Society, 18(2), 155-162.

[6] Okura, M., (2007). Coopetitive Strategies of Japanese Insurance Firms A Game Theory Approach. International Studies of Management \& Organization, 27(2), 53-69.

[7] Gu, D., (2010). A Game Theory Approach to Target Tracking in Sensor Networks. IEEE Transactions on Systems, Man, and Cybernetics, Part B (Cybernetics), Vol. 41, Issue 1, 2-13.

[8] Rezazadeh, A., Zhang, L., Reniers, G., Khakzad, N., Cozzani, V, (2017). Optimal Patrol Scheduling of Hazardous Pipelines Using Game Theory. Process Safety and Environmental Protection, Vol.109, 242-256.

[9] İzgi, B., Özkaya, M., (2019). A New Perspective to the Solution and Creation of Zero Sum Matrix Game with Matrix Norms. Applied Mathematics and Computation, 341, 148159.

[10] Özkaya, M., (2018). The Roles of Matrix Norms in the Game Theory. Istanbul Technical University. Graduate School of Science, Engineering and Technology, M.Sc. Thesis, 47s, Istanbul. 
[11] İzgi, B., Özkaya, M., (2018). An Enhanced View to the Solution of Nonzero Sum Bimatrix Games Using Matrix Norms, (İncelemede).

[12] Birgen, B. J., (2015). The Uniqueness of Rock-Paper-Scissors-Lizard-Spock, The College Mathematics Journal, Vol.46(4), 270-273.

[13] Leyton-Brown, K., Shoham, Y., 2008, Essentials of Game Theory, Morgan\&Claypool Publishers, 88s.

[14] Ferguson, T.S., 2014. Game Theory, Mathematics Department UCLA, 2nd Edition.
[15] Eves, H., 1968, Elementary Matrix Theory.Allyn and Bacon Inc., $325 \mathrm{~s}$.

[16] https://www.kisspng.com/png _ n rockpaperscissors-hand-game-4041919/ (Erişim Tarihi. 25.09.2018)

[17] https://puzzlewocky.com/parlor-games/rock- paper-scissors-lizard-spock/ (Erişim Tarihi. 25.09.2018)

[18] https://www.math.ucla.edu/ tom/gamesolve. html (Erişim Tarihi. 12.10.2018)

[19] Ferguson, T.S., (2014). Game Theory, Mathematics Department UCLA, Part III, 2nd Edition. 